\title{
Hypereosinophilic obliterative bronchiolitis: a distinct, unrecognised syndrome
}

\author{
Jean-François Cordier*\#,ף, Vincent Cottin*,\#,ף, Chahéra Khouatra*\#, \\ Didier Revel ${ }^{*}{ }^{,},+$, , Clément Proust* ${ }^{*}{ }^{,},+$, Nathalie Freymond*,\#, \\ Françoise Thivolet-Béjui*, ${ }^{\star,}$, and Jean-Charles Glérant*, $f$
}

ABSTRACT: Biopsy-proven cases of eosinophilic bronchiolitis have only been reported in isolation, and all come from Japan.

We present six patients with hypereosinophilic obliterative bronchiolitis (HOB), defined by the following criteria: 1) blood eosinophil cell count $>1 \mathrm{G} \cdot \mathrm{L}^{-1}$ and/or bronchoalveolar lavage eosinophil count $>25 \%$; 2) persistent airflow obstruction despite high-dose inhaled bronchodilators and corticosteroids; and 3 ) eosinophilic bronchiolitis at lung biopsy $(n=1)$ and/or direct signs of bronchiolitis (centrilobular nodules and branching opacities) on computed tomography $(n=6)$.

Chronic dyspnoea and cough which was often severe, without the characteristic features of asthma, were the main clinical manifestations. Atopy and asthma were present in the history of three and two patients, respectively. One patient met biological criteria of the lymphoid variant of idiopathic hypereosinophilic syndrome. Mean blood eosinophil cell count was $2.7 \mathrm{G} \cdot \mathrm{L}^{-1}$ and mean eosinophil differential percentage at bronchoalveolar lavage was $63 \%$. Mean initial forced expiratory volume in $1 \mathrm{~s}$ /forced vital capacity ratio was $50 \%$, normalising with oral corticosteroid therapy in all patients. HOB manifestations recurred when oral prednisone was decreased to 10$20 \mathrm{mg} \cdot$ day $^{-1}$, but higher doses controlled the disease.

$\mathrm{HOB}$ is a characteristic entity deserving to be individualised among the eosinophilic respiratory disorders. Thorough analysis is needed to determine whether unrecognised and/or smouldering HOB may further be a cause of irreversible airflow obstruction in chronic eosinophilic respiratory diseases.

KEYWORDS: Allergic bronchopulmonary aspergillosis, asthma, bronchiolitis, Churg-Strauss syndrome, eosinophilic lung disease, eosinophilic pneumonia

$\mathbf{T}$ he spectrum of eosinophilic bronchopulmonary diseases [1], both primary and secondary, comprises parenchymal disorders (acute and chronic eosinophilic pneumonias) and eosinophilic airway disorders, including eosinophilic bronchitis and the eosinophilic phenotype of asthma. Some eosinophilic disorders, such as allergic bronchopulmonary aspergillosis (ABPA) and Churg-Strauss syndrome (CSS), may involve both parenchymal and airway structures [2]

Eosinophilic bronchiolitis has been reported in a nonasthmatic Japanese patient with a 3-year history of diffuse pan-bronchiolitis, who developed blood $\left(6.9 \mathrm{G} \cdot \mathrm{L}^{-1}\right)$ and alveolar eosinophilia (with 91\% eosinophils in bronchoalveolar lavage (BAL)), as well as airflow obstruction [3]. High-resolution computed tomography (HRCT) revealed diffuse, poorly defined centrilobular nodules, thickening of bronchial and bronchiolar walls and mild bronchiectasis; lung biopsy disclosed eosinophilic bronchiolitis. Airflow obstruction improved with corticosteroids but relapsed upon tapering. A few additional isolated cases, all from Japan, have been described in another report [4]. However, whether eosinophilic bronchiolitis corresponds to a specific condition has not been established.

In this article, we present six patients with a relevant clinical, radiological and functional syndrome, who could not be classified into any recognised condition and who especially manifested features quite distinct from eosinophilic asthma. We propose the term hypereosinophilic obliterative bronchiolitis (HOB) and suggest provisional working diagnostic criteria to delineate the condition.

\section{AFFLLIATIONS}

*National Reference Centre for Rare Pulmonary Diseases, Louis Pradel University Hospital, Lyon,

\#Dept of Pneumology, Louis Pradel University Hospital, Lyon, "Dept of Respiratory Medicine, Université Claude Bernard, Lyon, ${ }^{+}$Dept of Radiology, Hospices Civils de Lyon, Lyon,

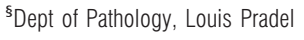
University Hospital, Lyon, and ${ }^{f}$ Dept of Pulmonary Physiology, Louis Pradel Univesity Hospital, Lyon, France.

CORRESPONDENCE

J-F. Cordier

Louis Pradel University Hospital, National Reference Centre for Rare Pulmonary Diseases Université Claude Bernard 69677 Lyon (Bron) Cedex France

E-mail: jean-francois.cordier@

chu-lyon.fr

Received:

June 272012

Accepted after revision:

Aug 202012

First published online:

Dec 202012 


\section{MATERIALS AND METHODS Definition of cases}

HOB diagnosis included the following three criteria. 1) Blood eosinophil cell count $>1 \mathrm{G} \cdot \mathrm{L}^{-1}$ (and/or BAL eosinophil differential cell count $>25 \%$ ). 2) Persistent airflow obstruction on lung function tests, defined by post-bronchodilator forced expiratory volume in $1 \mathrm{~s}$ (FEV1)/forced vital capacity (FVC) ratio $<70 \%$ and $\mathrm{FEV} 1<80 \%$ predicted, not improved by $4-$ 6 weeks of inhaled corticosteroid therapy $\left(2000 \mu \mathrm{g} \cdot\right.$ day $^{-1}$ of beclometasone or equivalent). Other functional features of obliterative bronchiolitis may comprise decreased forced expiratory flow at $25-75 \%$ of $\mathrm{FVC}$ and increased residual volume to total lung capacity ratio. 3) Lung biopsy demonstrating inflammatory bronchiolitis with prominent bronchiolar wall infiltration by eosinophils (associated or not with alveolar and/or vessel infiltration by eosinophils) and/or characteristic direct HRCT features of bronchiolitis, as defined below. Pulmonary function tests were performed according to European Respiratory Society recommendations.

\section{Imaging}

All patients underwent chest radiography and spiral HRCT in the imaging department of Louis Pradel University Hospital (Lyon, France) with a multidetector computed tomography (CT) system (Philips B64; Phillips, Eindhoven, the Netherlands). All HRCT data were reviewed collectively by three authors (D. Revel, J-F. Cordier and V. Cottin); independent review of HRCT data by another radiologist (C. Proust) showed agreement on $88 \%$ of items of direct bronchiolitis features. Maximum intensity projection post-processing [5] was performed to improve the detection of centrilobular nodules. Imaging features were described according to the Fleischner Society guidelines [6]. Direct features of bronchiolitis were the following: poorly defined centrilobular nodules, branching opacities and tree-in-bud pattern. Indirect signs of bronchiolitis were mosaic attenuation on inspiratory $\mathrm{CT}$ and air-trapping pattern on end-expiration CT consisting of a patchwork of regions of differing attenuation, and bronchial wall thickening.

\section{Study design}

Data were acquired retrospectively. According to French legislation, informed consent is not required for retrospective data collection corresponding to current practice. However, the database was anonymous and complied with requirements of the Commission Nationale de l'Informatique et des Libertés, the organisation dedicated to privacy, information technology and civil rights in France.

\section{RESULTS}

\section{Individual cases}

The clinical features of six patients are reported below, with further history and investigations, lung function tests and HRCT findings presented in tables 1, 2 and 3, respectively.

\section{Patient 1}

A 46-year-old male presented in August 2011 with persistent, chronic, exhausting cough. Spirometry was normal. He was given oral corticosteroid (OCS) therapy over a few weeks which resulted in the disappearance of the cough. Shortly after stopping OCS therapy, severe cough relapsed with further dyspnoea and airflow obstruction on pulmonary function tests.
Blood eosinophil count was $1.9 \mathrm{G} \cdot \mathrm{L}^{-1}$, and BAL differential cell count was $50 \%$ eosinophils. Blood analysis disclosed that $7.8 \%$ of total lymphocytes had a CD3+CD4+CD7- surface immunophenotype with further oligoclonal (175-183-193 bp) T-cell receptor- $\gamma$ VG9J1J2 re-arrangement. HRCT demonstrated direct bronchiolitis features (fig. 1). Oral prednisone was resumed and decreased progressively from 40 to $10 \mathrm{mg} \cdot$ day $^{-1}$. The patient was thereafter asymptomatic with normal lung function.

\section{Patient 2}

A 41-year-old female presented in June 2007 with nasal congestion, severe, permanent cough with viscous mucous sputum and occasional wheezing. In March 2008, her symptoms persisted despite intermittent OCS therapy. Spirometry and HRCT were normal. Fibreoptic bronchoscopy disclosed small, whitish mucosal granulations disseminated over the mucosa of the trachea and main bronchi (fig. 2). Blood eosinophil count was $1.5 \mathrm{G} \cdot \mathrm{L}^{-1}$ and BAL differential count was $15 \%$ eosinophils. Inhaled budesonide ( $400 \mu \mathrm{g}$ three times daily) resulted in clinical improvement. A diagnosis of eosinophilic bronchitis was considered. She was lost to follow-up, and received various treatments, including methotrexate, in addition to OCS therapy; however, the clinical manifestations relapsed as soon as prednisone was decreased below $20 \mathrm{mg} \cdot \mathrm{day}^{-1}$. In May 2010, the patient manifested severe airflow obstruction and hypoxaemia as well as direct HRCT features of bronchiolitis. Blood eosinophil count was $1.4 \mathrm{G} \cdot \mathrm{L}^{-1}$, and BAL differential cell count was $60 \%$ eosinophils. She received prednisone $40 \mathrm{mg} \cdot \mathrm{day}^{-1}$ progressively with major clinical and functional improvement. Treatment was tapered, but dyspnoea and airflow obstruction re-appeared at a dose of $25 \mathrm{mg} \cdot \mathrm{day}^{-1}$ of prednisone. The patient was started on omalizumab off-label (total immunoglobulin (Ig)E level was $150 \mathrm{mg} \cdot \mathrm{L}^{-1}$ ), with better control of symptoms, allowing tapering of prednisone to alternate daily doses of 10 and $15 \mathrm{mg}$ day $^{-1}$. Again, lung function deteriorated, FEV1 decreased from 3.1 (111\% pred) to $2.3 \mathrm{~L}$ ( $83 \%$ pred), and eosinophil count increased to $0.8 \mathrm{G} \cdot \mathrm{L}^{-1}$. Azathioprine $\left(150 \mathrm{mg} \cdot \mathrm{day}^{-1}\right)$ was added, and prednisone augmented to $15 \mathrm{mg} \cdot \mathrm{day}^{-1}$, resulting in FEV1 correction (2.9 L) within 3 months. At the most recent measurement, in June 2012, FEV1 was 2.43 L (89\% pred), despite $17.5 \mathrm{mg}$ day $^{-1}$ of prednisone.

\section{Patient 3}

A 47-year-old male with a history of exercise-related asthma since 1994 (controlled by inhaled corticosteroid and bronchodilator) presented in May 2009 with increasingly severe cough and migratory pulmonary opacities, mild features of bronchiolitis on chest imaging and elevated eosinophil blood cell count $\left(2.7 \mathrm{G} \cdot \mathrm{L}^{-1}\right)$. In October 2009 , dyspnoea intensified, with airflow obstruction (table 2). HRCT demonstrated direct bronchiolitis features with further bronchiectasis and mucus plugging (fig. 3). Multiple whitish nodules of the mucosa of the trachea and of most bronchi were apparent on fibreoptic bronchoscopy; biopsy disclosed ulcerated mucosa with areas of necrosis and prominent eosinophilic inflammation. Peripheral eosinophil blood cell count was $2.2 \mathrm{G} \cdot \mathrm{L}^{-1}$, and BAL differential cell count was $69 \%$ eosinophils. No bacteria, fungi or moulds were evident on direct examination or culture. Treatment with $40 \mathrm{mg}$ of oral prednisone once daily was initiated, with rapid clinical and functional improvement. Progressive decrease of the prednisone dose to 10 and 


\begin{tabular}{|c|c|c|c|c|c|c|}
\hline Patient & $\begin{array}{l}\text { History of atopy and/or } \\
\text { asthma and nasal } \\
\text { polyposis }\end{array}$ & Skin tests & $\begin{array}{l}\text { Total } \lg \mathrm{E}^{\#} \text { (maximum } \\
\text { value) } \mathrm{kU} \cdot \mathrm{L}^{-1}\end{array}$ & $\begin{array}{l}\text { Aspergillus fumigatus } \\
\text { antibodies (IgG and } \lg E \text { ) }\end{array}$ & Pack-years & Quit date \\
\hline 1 & $\begin{array}{l}\text { Conjunctivitis and rhino- } \\
\text { sinusitis in childhood } \\
\text { (desensitisation) }\end{array}$ & $\begin{array}{c}\text { Positive (grass, short } \\
\text { ragweed) } \\
\text { Negative for } A \text {. fumigatus }\end{array}$ & 1709 & Negative & 20 & July 2011 \\
\hline 2 & None & $\begin{array}{c}\text { Negative, especially for } \\
\text { A. fumigatus }\end{array}$ & 90 & Negative & 0 & \\
\hline 3 & $\begin{array}{l}\text { Rhinitis in childhood } \\
\text { Exercise-related asthma } \\
\text { Nasal polyposis requiring } \\
\text { surgery }\end{array}$ & $\begin{array}{c}\text { Positive (grass) } \\
\text { Negative for A. fumigatus }\end{array}$ & 486 & $\begin{array}{c}\text { Negative (July 2007) } \\
\text { Positive (February 2012) }\end{array}$ & 17 & 1994 \\
\hline 5 & None & $\begin{array}{l}\text { Negative, especially for } \\
\text { A. fumigatus }\end{array}$ & 101 & Negative & 12 & 2006 \\
\hline 6 & None & $\begin{array}{l}\text { Negative, especially for } \\
\text { A. fumigatus }\end{array}$ & 920 & $\begin{array}{c}\text { IgE positive: } 3.58 \mathrm{m3}(\mathrm{n} \\
<0.10) \\
\text { IgG: negative }\end{array}$ & 20 & 2009 \\
\hline
\end{tabular}

Data are presented as $\mathrm{n} .{ }^{*}$ : normal IgE values are $<150 \mathrm{kU} \cdot \mathrm{L}^{-1}$ or $<391 \mathrm{IU} \cdot \mathrm{mL}^{-1}$; ${ }^{\bullet}$ : value given in $\mathrm{IU} \cdot \mathrm{mL}^{-1}$

\section{TABLE 2 Selected lung function tests}

\begin{tabular}{|c|c|c|c|c|c|c|}
\hline Patient & Date & FEV 1 L (\% pred) & Post-bronchodilator FEV 1 L & $\mathrm{FEV}_{1} / \mathrm{FVC} \%$ & $\begin{array}{c}\text { FEF } 25-75 \% \mathrm{~L} \cdot \mathrm{s}^{-1} \\
\text { (\% pred) }\end{array}$ & $\mathrm{RV} / \mathrm{TLC} \%$ \\
\hline \multirow[t]{2}{*}{1} & Aug 23, 2011 & $3.23(103)$ & 3.23 & 87 & $4.46(115)$ & \\
\hline & Nov 9, 2011 & $3.00(95)$ & 2.9 & 80 & $3.94(102)$ & \\
\hline \multirow[t]{2}{*}{2} & May 28, 2010 & $0.87(31)$ & 1.23 & 45 & $0.44(13)$ & 65 (193) \\
\hline & July 1, 2010 & $3.07(111)$ & & 71 & $2.85(82)$ & \\
\hline \multirow[t]{2}{*}{3} & Oct 23, 2009 & $2.68(71)$ & 2.68 & 58 & $1.34(32)$ & \\
\hline & Feb 17,2010 & $3.93(103)$ & 4.48 & 67 & $2.47(60)$ & \\
\hline \multirow[t]{3}{*}{4} & Jan 12, 2006 & $1.98(76)$ & 2.05 & 58 & $3.42(21)$ & \\
\hline & July 13, 2006 & $2.76(105)$ & 3.14 & 72 & & \\
\hline & April 16, 2012 & $2.53(103)$ & 2.69 & 69 & & \\
\hline 5 & Sept 12, 2007 & $0.59(24)$ & 0.61 & 34 & $0.21(6)$ & \\
\hline \multirow{6}{*}{6} & March 31, 1992 & $3.45(96)$ & 3.62 & 89 & & \\
\hline & May 6, 1996 & $3.11(89)$ & 3.20 & 80 & & \\
\hline & June 7, 2004 & $2.66(82)$ & 2.71 & 68 & & \\
\hline & April 22, 2008 & $1.97(63)$ & 2.07 & 65 & & \\
\hline & Feb 9, 2010 & $1.20(39)$ & 1.25 & 38 & $0.40(15)$ & $56(154)$ \\
\hline & July 19, 2012 & $1.74(58)$ & $1.74(58)$ & 48 & $1.03(30)$ & $46(124)$ \\
\hline
\end{tabular}

FEV1: forced expiratory volume in $1 \mathrm{~s}$; \% pred: \% predicted; FVC: forced vital capacity; FEF25-75\%: forced expiratory flow at 25-75\% of FVC; RV: residual volume; TLC: total lung capacity. 


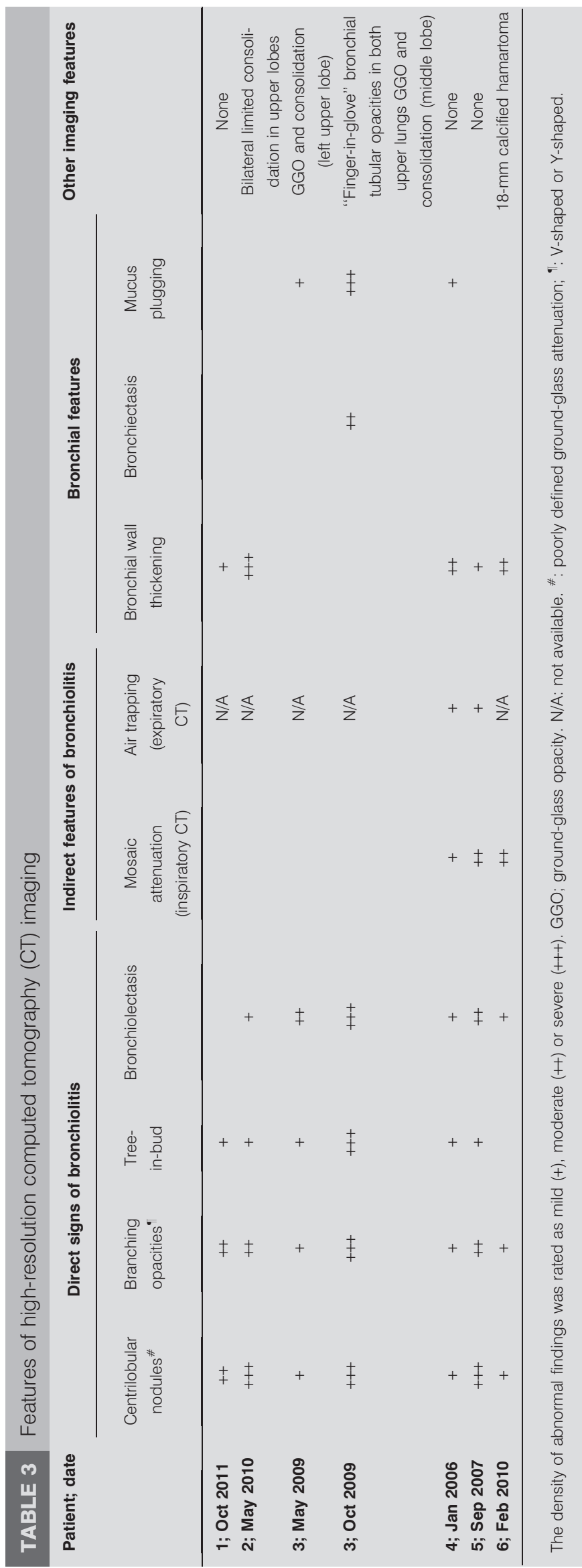

$15 \mathrm{mg} \cdot$ day $^{-1}$ every other day provided sub-optimal clinical control, with FEV1 of $3.3 \mathrm{~L}$ (86\% pred) and blood eosinophil cell count of $0.8 \mathrm{G} \cdot \mathrm{L}^{-1}$. The patient informed us that he had stopped inhaled corticosteroids for several months. Resuming inhaled therapy (with unchanged dose of prednisone) normalised FEV1 (4.5 L, 118\% pred).

\section{Patient 4}

A 44-year-old nonasthmatic female presented at another institution in 2005 with persistent, productive cough. Alveolar consolidation was seen in the right middle lobe on imaging. The peripheral blood eosinophil count was $2.9 \mathrm{G} \cdot \mathrm{L}^{-1}$, with $78 \%$ eosinophils on BAL differential cell count. Retrospectively, she was found to have a long-standing history of blood eosinophilia, with $0.9 \mathrm{G} \cdot \mathrm{L}^{-1}$ eosinophils in 1998 . When she was referred for evaluation, peripheral eosinophils were $2 \mathrm{G} \cdot \mathrm{L}^{-1}$, and airflow was obstructed (table 2 ). HRCT revealed direct bronchiolitis features. The patient improved rapidly on OCS therapy, with long-term stable lung function while taking $<10 \mathrm{mg} \cdot$ day $^{-1}$ of prednisone. In April 2012, while on $5 \mathrm{mg} \cdot$ day $^{-1}$ of oral prednisone, FEV1 was slightly impaired and eosinophil blood cell count was $1.04 \mathrm{G} \cdot \mathrm{L}^{-1}$.

\section{Patient 5}

A 46-year-old female was referred in September 2007 for progressive dyspnoea over the previous 6 months despite inhaled bronchodilator and high-dose inhaled corticosteroid. Airflow was found to be severely obstructed on lung function tests, and 6-min walk test distance was only $278 \mathrm{~m}$. Peripheral blood eosinophil count was $2.4 \mathrm{G} \cdot \mathrm{L}^{-1}$, and BAL differential cell count was $35 \%$ eosinophils. HRCT demonstrated direct bronchiolitis features. OCS therapy resulted in rapid improvement of both symptoms and lung function (table 2). However, airflow obstruction recurred with tapering of OCS therapy.

\section{Patient 6}

A 40-year-old male presented in November 1991 with intermittent cough, progressive dyspnoea and airflow obstruction (table 2). In February 1992, symptoms and airflow obstruction worsened. Peripheral blood eosinophil count was $5.4 \mathrm{G} \cdot \mathrm{L}^{-1}$ and BAL differential cell count was $85 \%$ eosinophils. Infiltrative opacities were apparent on chest radiography. Lung biopsy in March 1992 was reported as "diffuse eosinophilic bronchioloalveolitis". OCS therapy, initiated at $60 \mathrm{mg} \cdot \mathrm{day}^{-1}$ of oral prednisolone, normalised lung function 1 month later. However, OCS therapy could not be decreased below $15 \mathrm{mg} \cdot$ day $^{-1}$ because of relapsing bronchopulmonary manifestations and airflow obstruction. The patient received various treatments in addition to OCS therapy in other institutions, including hydroxycarbamide, imatinib and $\alpha$-interferon.

In February 2006, blood eosinophil differential count was $18 \%$ while the patient was receiving $17.5 \mathrm{mg} \cdot \mathrm{day}^{-1}$ of oral prednisolone. In February 2010, severe airflow obstruction persisted on $15 \mathrm{mg} \cdot$ day $^{-1}$ of prednisolone, inhaled fluticasone $500 \mu \mathrm{g}$ with salmeterol $50 \mu \mathrm{g}$ twice a day and $500 \mathrm{mg} \cdot$ day $^{-1}$ of hydroxycarbamide. The conclusion of lung biopsy review was: diffuse eosinophilic pulmonary disease with eosinophilic granulomatous vasculitis involving the small arteries and capillaries, 

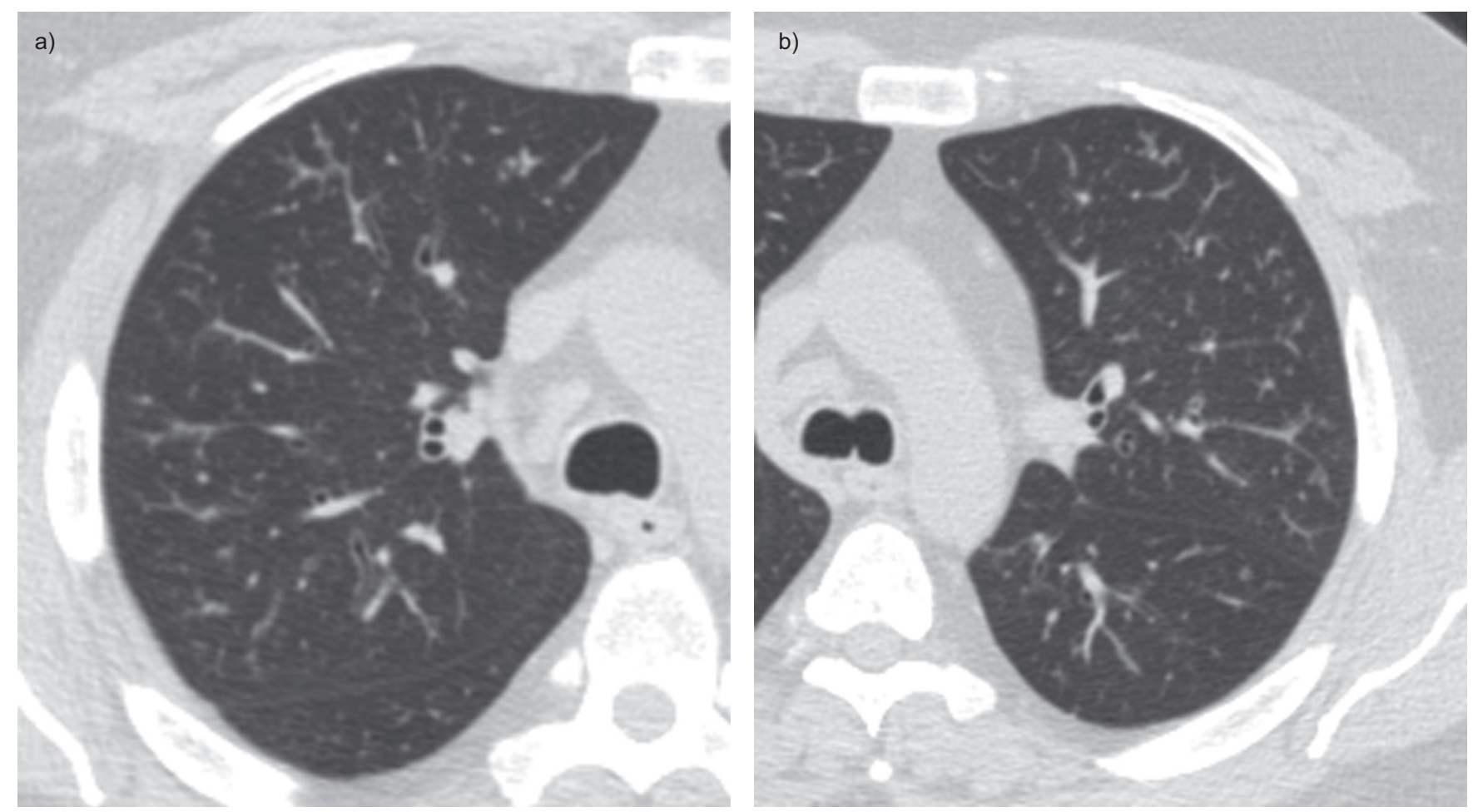

FIGURE 1. Volumetric computed tomography scans with high resolution of the chest in patient 1 , demonstrating a tree-in-bud pattern and centrilobular nodules in the a) right and b) left lungs.

eosinophilic bronchiolitis severely impairing the bronchiolar walls with intraluminal eosinophilia (fig. 4) and eosinophilic alveolitis with eosinophilic abscesses, compatible with a diagnosis of "lung-limited CSS". Airflow obstruction progressively worsened subsequently, despite OCS therapy $>15 \mathrm{mg} \cdot \mathrm{day}^{-1}$ of prednisone. Transient increase in OCS therapy $\left(50 \mathrm{mg} \cdot \mathrm{day}^{-1}\right.$ for 3 weeks, then $40 \mathrm{mg} \cdot \mathrm{day}^{-1}$ for 3 weeks) resulted in major functional improvement at the last visit (table 2).

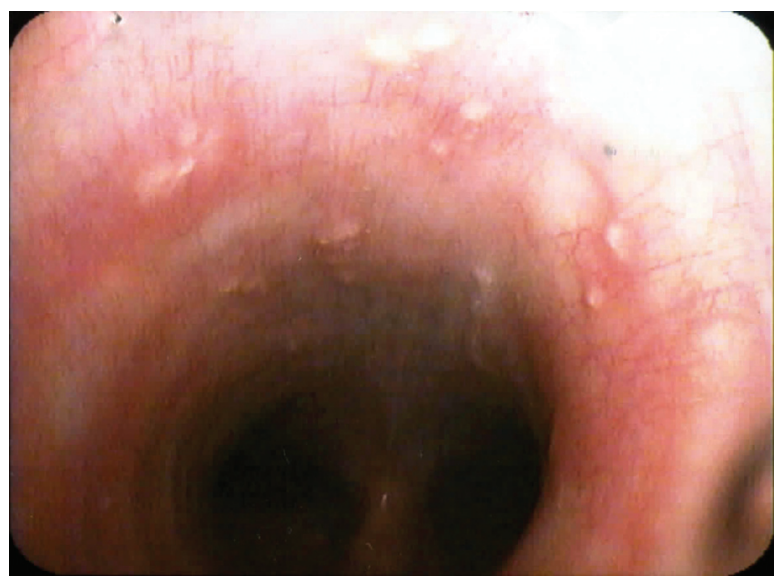

FIGURE 2. Fibreoptic bronchoscopy in patient 2, showing white mucosal granulations of the tracheal mucosa. A similar pattern was observed in patient 3 , corresponding histiopathologically to ulcerated tracheal and bronchial mucosa with areas of necrosis and prominent eosinophilic inflammation.

\section{Group analysis}

Clinical manifestations and lung function

The respiratory manifestations seen were clearly distinct from those of asthma, and patients did not particularly have recurrent paroxystic symptoms of dyspnoea and wheezing (asthma attacks). Cough, often severe, and acute or chronic dyspnoea (with transient control while under short-term OCS therapy) were the major symptoms. Airflow was obstructed in all patients (table 2). The response to inhaled short-acting bronchodilators was significant in two out of six patients, but lung function did not normalise in any patients with prolonged therapy involving inhaled long-acting bronchodilators and high-dose inhaled corticosteroids. In contrast, OCS therapy resulted in correction of airflow obstruction in all cases.

No patient presented extrarespiratory, eosinophil-related, systemic manifestations. No clinical criteria of pulmonary, especially viral, infections were apparent at diagnosis. No patients were taking drugs with possible iatrogenic eosinophilic outcomes.

\section{Biological findings}

Mean eosinophil blood cell count was $2.6 \mathrm{G} \cdot \mathrm{L}^{-1}$ (range 1.4$5.4 \mathrm{G} \cdot \mathrm{L}^{-1}$ ) at $\mathrm{HOB}$ diagnosis and the BAL eosinophil differential cell count was $63 \%$ (range $35-85 \%$ ). C-reactive protein level was elevated in only one patient. Stool analysis and serology for parasitic infections were negative in all patients. Systematic immunological testing included antinuclear antibodies (all negative), antineutrophil cytoplasmic antibodies (all negative), rheumatoid factor (positive in three out of six patients) and anti-citrullinated peptide antibodies (positive with a low titre in one patient). No patients met diagnostic 

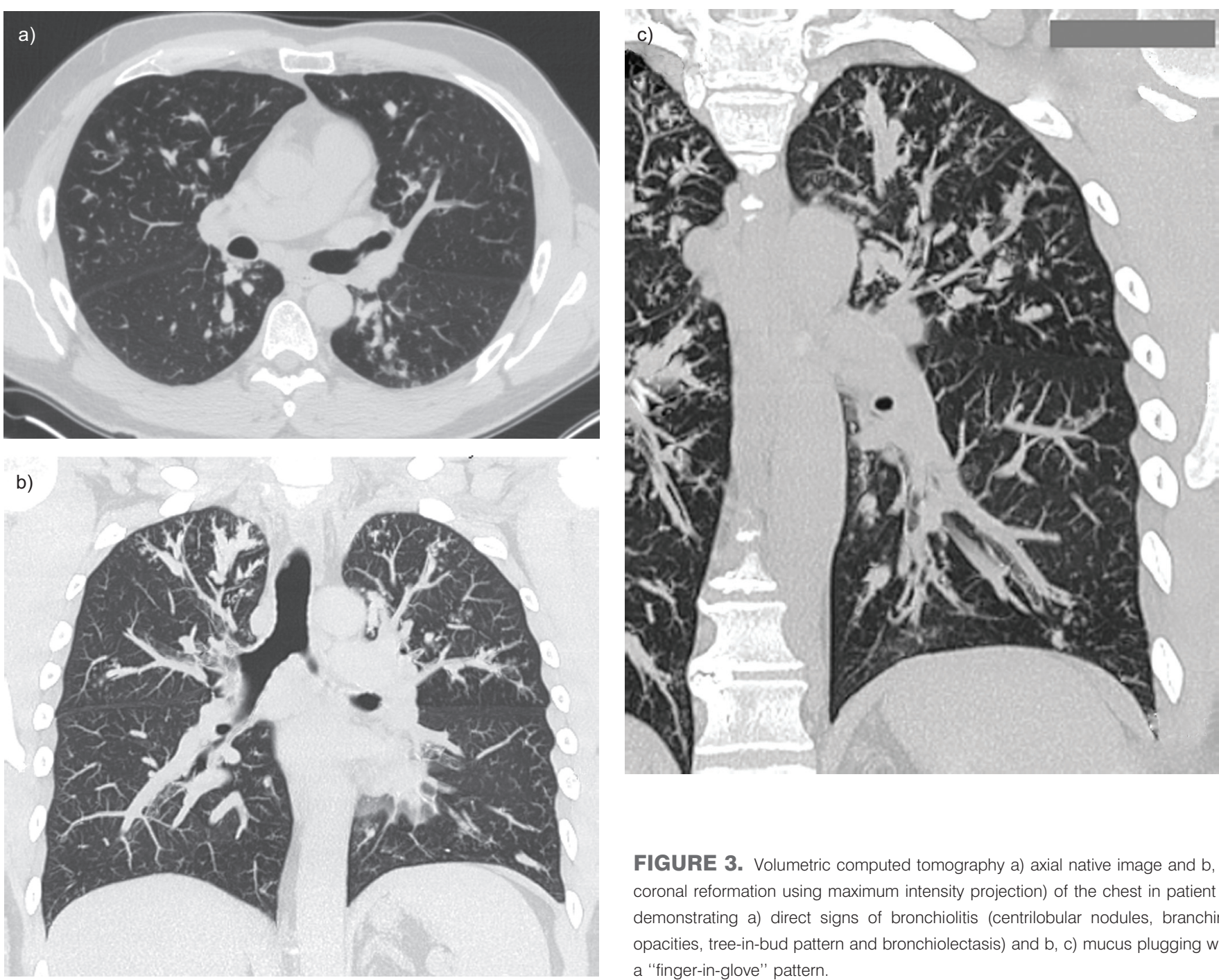

criteria for connective tissue disease or systemic vasculitis. Total IgE was elevated in five out of six cases. IgE specific to Aspergillus fumigatus was negative in all cases except patient 6, who did not fulfil the diagnostic criteria of ABPA. Skin tests for Aspergillus were negative in five out of five patients. T-cell clonality was found in one out of six patients (patient 1, see above). FIP1L1-PDGFR $\alpha$ (FIP1-like1-platelet-derived growth factor receptor- $\alpha$ ), Bcr-abl fusion transcripts and Jak2 (Janus kinase-2) mutations were present in none out of six, none out of three and none out of three cases, respectively. Serum interleukin-5 level was elevated in one out of six cases. Tryptase and vitamin B12 serum levels were normal in six out of six and five out of five cases, respectively.

\section{Imaging}

Chest radiography did not generally contribute to the diagnosis of $\mathrm{HOB}$, but showed a finger-in-glove sign in the right upper lobe in patient 3. Direct signs of bronchiolitis were the predominant abnormal features on HRCT in all patients, with ill-defined centrilobular nodules of ground-glass attenuation (in six out of six patients), branching opacities (V-shaped or Yshaped) (six out of six patients) and tree-in-bud pattern (five out

of six patients) (table 3). Mosaic attenuation was apparent on inspiratory $\mathrm{CT}$ in two patients, and air trapping was observed on end-expiratory CT in two patients tested. Limited areas of ground-glass attenuation or consolidation were seen in two patients, and bronchial abnormalities, especially bronchial wall thickening, were noted in five patients. The finger-in-glove sign was discerned on HRCT in patient 3, with mucus density measurements ranging from 42 to $63 \mathrm{HU}$ and mucus plugs of similar density to that of skeletal muscles. Mildly enlarged mediastinal lymph nodes $(>10 \mathrm{~mm})$ were present in all patients. No patient had pleural or pericardial effusion. Sinus imaging in all patients showed pan-sinusitis in two cases and para-sinusal and frontal sinusitis in two cases.

Follow-up

OCS therapy, initiated at a median dose of $0.7 \mathrm{mg} \cdot \mathrm{kg}^{-1} \cdot \mathrm{day}^{-1}$ of prednisone (range $0.5-1.1 \mathrm{mg} \cdot \mathrm{kg}^{-1} \cdot \mathrm{day}^{-1}$ ), resulted in rapid improvement of clinical manifestations in all patients, with a dramatic fall in blood eosinophil cell count to normal values. Functional improvement was dramatic upon OCS therapy in all cases. The FEV1/FVC ratio returned to normal in all patients on corticosteroid therapy, with a median FEV1 

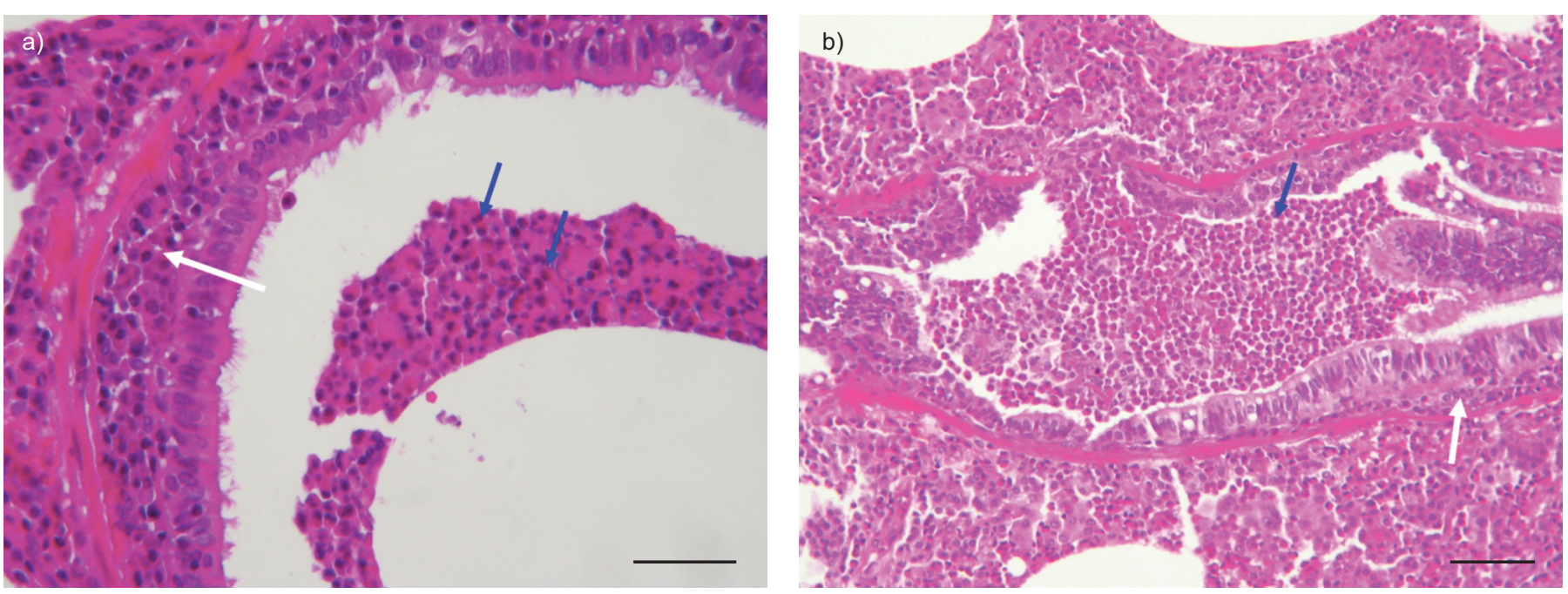

FIGURE 4. Histopathological analysis of lung biopsy specimen in patient 6, demonstrating hypereosinophilic bronchiolitis, with eosinophil-rich infiltrates of the submucosa (white arrows), and accumulation (plugging) of inflammatory cells with abundant eosinophils (blue arrows) in the bronchiolar lumen. Hemalun-Eosine Saffron. Scale bars $=40 \mu \mathrm{m}$

increase of $1.7 \mathrm{~L}$. Complete or near-complete resolution of direct HRCT signs of bronchiolitis on HRCT was obtained in all patients, who were followed for a median of 58 months (range 10-247 months). Airflow obstruction recurred five times in patient 2 while receiving $12.5 \mathrm{mg} \cdot \mathrm{day}^{-1}$ of prednisone, and five and four times, respectively, in patients 4 and 5 after they had interrupted OCS therapy. At the last visit, all patients were still receiving OCS therapy with a median dose of $10 \mathrm{mg} \cdot$ day $^{-1}$ (range $2.5-12.5 \mathrm{mg} \cdot \mathrm{day}^{-1}$ ), and all were on inhaled corticosteroids and bronchodilators. Airflow obstruction, despite inhaled therapy, was present only in patient 6 with poor compliance with therapy. In one patient, azathioprine and off-label omalizumab were initiated because of recurrent airflow obstruction despite a daily prednisone dose $>20 \mathrm{mg} \cdot$ day $^{-1}$.

\section{DISCUSSION}

The above cases share common characteristics which collectively delineate a distinct entity deserving recognition as an original syndrome. We propose the term HOB to describe this entity, defined by: 1) blood hypereosinophilia $>1 \mathrm{G} \cdot \mathrm{L}^{-1}$ and/or BAL eosinophilia $>25 \%$; 2) airflow obstruction not improved by a prolonged course of inhaled bronchodilators and corticosteroids; and 3) characteristic direct signs of bronchiolitis on HRCT imaging and/or at lung biopsy. Of note, peripheral blood eosinophilia surpassed $1.5 \mathrm{G} \cdot \mathrm{L}^{-1}$ and BAL eosinophilia was $>40 \%$ in five out of six cases, indicating that $\mathrm{HOB}$ is characterised by marked eosinophilia ("hypereosinophilia"), and these thresholds may be appropriate as future diagnostic criteria.

Bronchiolitis is defined pathologically as a bronchiolar cellular inflammatory process with further possible bronchiolar fibrosis [7]. A limitation of this study was that a lung biopsy was not mandatory for the diagnosis of bronchiolitis, provided that both airflow obstruction and characteristic direct signs of bronchiolitis on HRCT were present $[6,8,9]$. Although a definitive diagnosis of bronchiolitis relies on biopsy, this invasive procedure is currently rarely performed in such a setting. The terms bronchiolitis obliterans and obliterative bronchiolitis are considered to be synonymous; however, we usually employ the term obliterative bronchiolitis to designate the clinical functional condition characterised by airflow obstruction resulting from bronchiolitis [10], while the pathological condition is usually designated bronchiolitis obliterans. The characteristic computed tomography direct features of bronchiolitis have been well established [8], with: 1) a pattern of ill-defined nodules of ground-glass attenuation (observed in sub-acute hypersensitivity pneumonitis and CSS) corresponding pathologically to peribronchiolar inflammation; and 2) a pattern of centrilobular nodules with a tree-in-bud appearance and bronchial wall thickening (as seen in Mycobacterium infection and ABPA), which correspond pathologically to the plugging of small airways or dilated bronchioles. The imaging pattern in HOB fitted the characteristic features of the latter. A mosaic pattern on inspiratory computed tomography (an indirect feature of bronchiolitis) was less prevalent $[6,7,11]$.

We consider that the cases reported above support the opinion that HOB is a syndrome, i.e. a group of symptoms and signs constituting a distinct clinical individuality without any univocal cause. HOB may be idiopathic, asthma associated, or part of an established condition of either unknown (e.g. CSS or clonal hypereosinophilic syndrome) or determined cause (e.g. ABPA or drug reaction).

HOB comprises distinctive features generally not observed in asthma, including imaging of bronchiolitis and a protracted course not responding to inhaled therapy. However, eosinophilic asthma and HOB may belong to the same spectrum of conditions, and it is likely that some HOB cases may previously have been considered to be severe, persistent asthma with particularly high eosinophilia and requiring prolonged OCS therapy. Asthma might precede HOB in some cases, as in patient 2. Centrilobular opacities have been reported in $21 \%$ of 50 asthmatic patients, more frequently in those with the most severe asthma [12]. Nasal polyposis, a hallmark of eosinophilic asthma [13], was apparent and severe (requiring surgery) in two patients. We have previously proposed to define hypereosinophilic asthma by the association of asthma and blood eosinophil cell count $>1 \mathrm{G} \cdot \mathrm{L}^{-1}$ 
(particularly $>1.5 \mathrm{G} \cdot \mathrm{L}^{-1}$ ) and/or eosinophils $>25 \%$ (especially $>40 \%$ ) at BAL differential cell count [14]. Hypereosinophilic asthma may be isolated or related to determined causes (iatrogenic, parasitic infections and ABPA) or conditions of unknown aetiology (idiopathic chronic eosinophilic pneumonia and CSS) [2, 14], and may lead to fixed airflow [15]. Recognising $\mathrm{HOB}$ and distinguishing it from asthma is worthwhile, as dramatic improvement is obtained by OCS therapy, which may need to be continued in the long-term to control airflow obstruction. Clearly, more attention should be paid in the future to searching for HOB features in patients with hypereosinophilic asthma as defined above. Interestingly, patients with the recently reported condition of asthmatic granulomatosis did not fit the criteria of $\mathrm{HOB}$, with blood eosinophilia $>1 \mathrm{G} \cdot \mathrm{L}^{-1}$ in only two out of 10 patients, airflow obstruction in six out of 10 patients and treein-bud pattern at HRCT in only one out of 10 patients [16].

Prominent bronchial wall thickening in five out of six patients was also present in Japanese cases of eosinophilic bronchiolitis $[3,4]$. Whitish tracheal and bronchial granulations were present in two patients, a finding seldom reported in eosinophilic lung disorders [17, 18], with ulcerative lesions and prominent eosinophilia at bronchial biopsy in one patient.

HOB was idiopathic in five out of six cases and coupled with the lymphoid variant of the hypereosinophilic syndrome in one case [1, 19], indicating that $\mathrm{HOB}$ may be a syndrome present in various conditions. HOB also shares some similarities with ABPA, with centrilobular nodules reported in 73$93 \%$ of patients [20, 21] and, commonly, bronchial wall thickening and mucus plugging with "finger-in-glove" pattern [22]. Bronchiectasis was present in only $\mathrm{HOB}$ patient 3 , but it can occur late in the course of ABPA [20]. The bronchial HRCT features in patient 3 were suggestive of ABPA, with upper lobe central bronchiectasis with mucoid impaction (finger-in-glove pattern). However, the skin-prick test for Aspergillus was negative, and $\mathrm{IgE}$ levels were $<500 \mathrm{IU} \cdot \mathrm{L}^{-1}$, thus theoretically excluding ABPA, although IgG and IgE specific to Aspergillus were slightly positive. Immunology features diagnostic of ABPA were not evident in the other HOB patients, and Aspergillus was not detected in BAL, sputum or lung biopsy.

Similarly, it is conceivable that the HOB syndrome may be found in patients with CSS. HRCT abnormalities in CSS include centrilobular nodules, bronchial wall thickening and bronchiectasis [2, 23-25], with the individualisation of two distinct imaging patterns: an airway pattern (consisting of small centrilobular nodules and tree-in-bud pattern, bronchial dilation, bronchial wall thickening and mosaic perfusion), and an airspace pattern (ground-glass opacities, consolidation and poorly defined nodules) [24]. Anomalies in $\mathrm{HOB}$ were very similar to the airway HRCT pattern reported in CSS, which is associated with airflow obstruction [24]. The classic pathological features of CSS, including a combination of eosinophilic infiltration, granulomatous inflammation and vasculitis, were present in patient 6, indicating a diagnosis of "lung-limited CSS". Airflow obstruction was persistent in $38 \%$ of CSS patients with $>3$ years of follow-up [26]. These observations collectively suggest that features compatible with HOB are common in patients with CSS.

We previously noted the case of a 28-year-old male who developed cough, dyspnoea, fever and airflow obstruction while taking minocycline [27], with ground-glass opacities, peribronchovascular thickening and micronodules compatible with bronchiolitis at CT. Blood cell count was $1.6 \mathrm{G} \cdot \mathrm{L}^{-1}$, and BAL differential cell count was 39\% eosinophils. Retrospectively, we consider that this patient probably had iatrogenic HOB.

OCS therapy was required in all patients because of persistent airflow obstruction. Clinical and functional improvement was spectacular on OCS therapy, with complete remission of airflow obstruction, whereas a prolonged course of inhaled bronchodilators and corticosteroids did not prevent gradual worsening of the disease. OCS therapy nevertheless needed to be continued over the long term, because of relapses (often progressive and insidious) when decreasing the daily doses of prednisone $<10$ $20 \mathrm{mg}$, which indicates that chronic HOB might be a cause of chronic, persistent airflow obstruction in eosinophilic lung diseases. Persistent airflow obstruction may significantly improve with increased doses of OCS therapy for several weeks, as shown in patient 6. Our provisional approach to HOB treatment consists of OCS therapy (in addition to inhaled bronchodilators and corticosteroids) at an initiating dose of $\sim 0.75 \mathrm{mg} \cdot \mathrm{kg}^{-1} \cdot \mathrm{day}^{-1}$ to rapidly normalise lung function, then decreased progressively over a few weeks with tight monitoring of both spirometry and blood eosinophil cell count to eventually adjust the dose to the lowest sufficient level, similar to the "tight control" step-down strategy in rheumatoid arthritis [28].

Whether untreated or undertreated smouldering $\mathrm{HOB}$ results in irreversible airflow obstruction is not presently known. Larger studies are needed to address this question and to further determine whether irreversible airflow obstruction, observed in some patients with disorders such as ABPA [20], CSS [26], idiopathic chronic eosinophilic pneumonia [29] and eosinophilic bronchitis [30] might derive from chronic and/or smouldering HOB.

\section{STATEMENT OF INTEREST}

None declared.

\section{ACKNOWLEDGEMENTS}

We thank M.L. Braud (Bourg-en-Bresse Hospital, Bourg-en-Bresse, France), L. Chalabreysse (Dept of Pathology, Louis Pradel Hospital, Lyon, France), B. Hohn (Chambéry Hospital, Chambéry, France), C. Massot (University Hospital, Grenoble, France), D. Rigaud (Grenoble), S. Turquier (Dept of Lung Physiology, Louis Pradel Hospital) and L. Vassort (Niort) for referring patients, communicating appropriate information as requested, and participating in patient diagnosis and management.

\section{REFERENCES}

1 Valent $\mathrm{P}$, Klion AD, Horny $\mathrm{HP}$, et al. Contemporary consensus proposal on criteria and classification of eosinophilic disorders and related syndromes. J Allergy Clin Immunol 2012; 130: 607-612.

2 Cordier JF, Cottin V. Eosinophilic pneumonias. In: Schwarz MI, King TE Jr, eds. Interstitial Lung Disease. 5th Edn. Shelton, People's Medical Publishing House USA, 2011; pp. 833-893.

3 Takayanagi N, Kanazawa M, Kawabata Y, et al. Chronic bronchiolitis with associated eosinophilic lung disease (eosinophilic bronchiolitis). Respiration 2001; 68: 319-322.

4 Fukushima Y, Kamiya K, Tatewaki M, et al. A patient with bronchial asthma in whom eosinophilic bronchitis and bronchiolitis developed during treatment. Allergol Int 2010; 59: 87-91. 
5 Beigelman-Aubry C, Hill C, Guibal A, et al. Multi-detector row CT and postprocessing techniques in the assessment of diffuse lung disease. Radiographics 2005; 25: 1639-1652.

6 Hansell DM, Bankier AA, Macmahon H, et al. Fleischner Society: glossary of terms for thoracic imaging. Radiology 2008; 246: 697-722.

7 Cottin V, Cordier JF. Bronchiolitis. In: Baughman RP, du Bois RM, eds. Diffuse Lung Disease. 2nd Edn. New York, Springer, 2012; pp. 343-363.

8 Abbott GF, Rosado-de-Christenson ML, Rossi SE, et al. Imaging of small airways disease. J Thorac Imaging 2009; 24: 285-298.

9 Rossi SE, Franquet T, Volpacchio M, et al. Tree-in-bud pattern at thin-section CT of the lungs: radiologic-pathologic overview. Radiographics 2005; 25: 789-801.

10 Cordier JF. Challenges in pulmonary fibrosis. 2: Bronchiolocentric fibrosis. Thorax 2007; 62: 638-649.

11 Ridge CA, Bankier AA, Eisenberg RL. Mosaic attenuation. AJR Am J Roentgenol 2011; 197: W970-W977.

12 Grenier P, Mourey-Gerosa I, Benali K, et al. Abnormalities of the airways and lung parenchyma in asthmatics: CT observations in 50 patients and inter- and intraobserver variability. Eur Radiol 1996; 6: 199-206.

13 Castro M, Mathur S, Hargreave F, et al. Reslizumab for poorly controlled, eosinophilic asthma: a randomized, placebo-controlled study. Am J Respir Crit Care Med 2011; 184: 1125-1132.

14 Cordier JF. Asthmes hyperéosinophiliques. [Hypereosinophilic asthmas.]. Rev Fr Allergol Immunol Clin 2004; 44: 92-95.

15 Freymond N, Kahn JE, Legrand F, et al. Clonal expansion of T cells in patients with eosinophilic lung disease. Allergy 2011; 66: 1506-1508.

16 Wenzel SE, Vitari CA, Shende M, et al. Asthmatic granulomatosis: a novel disease with asthmatic and granulomatous features. Am J Respir Crit Care Med 2012; 186: 501-507.

17 Kondo T, Suzuki H, Hirokawa Y, et al. Chronic eosinophilic pneumonia with small abscesses in the tracheo-bronchial mucosa and lung parenchyma. Intern Med 1992; 31: 391-393.

18 Matsushima H, Takayanagi N, Kurashima K, et al. Multiple tracheobronchial mucosal lesions in two cases of Churg-Strauss syndrome. Respirology 2006; 11: 109-112.
19 Roufosse F, Cogan E, Goldman M. Lymphocytic variant hypereosinophilic syndromes. Immunol Allergy Clin North Am 2007; 27: 389-413.

20 Agarwal R, Gupta D, Aggarwal AN, et al. Allergic bronchopulmonary aspergillosis: lessons from 126 patients attending a chest clinic in north India. Chest 2006; 130: 442-448.

21 Ward S, Heyneman L, Lee MJ, et al. Accuracy of CT in the diagnosis of allergic bronchopulmonary aspergillosis in asthmatic patients. AJR Am J Roentgenol 1999; 173: 937-942.

22 Martinez S, Heyneman LE, McAdams HP, et al. Mucoid impactions: finger-in-glove sign and other $\mathrm{CT}$ and radiographic features. Radiographics 2008; 28: 1369-1382.

23 Johkoh T, Muller NL, Akira M, et al. Eosinophilic lung diseases: diagnostic accuracy of thin-section CT in 111 patients. Radiology 2000; 216: 773-780

24 Kim YK, Lee KS, Chung MP, et al. Pulmonary involvement in Churg-Strauss syndrome: an analysis of CT, clinical, and pathologic findings. Eur Radiol 2007; 17: 3157-3165.

25 Furuiye M, Yoshimura N, Kobayashi A, et al. Churg-Strauss syndrome versus chronic eosinophilic pneumonia on high-resolution computed tomographic findings. J Comput Assist Tomogr 2010; 34: 19-22.

26 Cottin V, Khouatra C, Dubost R, et al. Persistent airflow obstruction in asthma of patients with Churg-Strauss syndrome and long-term follow-up. Allergy 2009; 64: 589-595.

27 Dussopt C, Mornex JF, Cordier JF, et al. Poumon éosinophile aigu après prise de minocycline. [Acute eosinophilic lung after a course of minocycline.]. Rev Fr Mal Respir 1994; 11: 67-70.

28 Bakker MF, Jacobs JW, Welsing PM, et al. Low-dose prednisone inclusion in a methotrexate-based, tight control strategy for early rheumatoid arthritis: a randomized trial. Ann Intern Med 2012; 156 329-339.

29 Jederlinic PJ, Sicilian L, Gaensler EA. Chronic eosinophilic pneumonia. A report of 19 cases and a review of the literature. Medicine (Baltimore) 1988; 67: 154-162.

30 Brightling CE, Woltmann G, Wardlaw AJ, et al. Development of irreversible airflow obstruction in a patient with eosinophilic bronchitis without asthma. Eur Respir J 1999; 14: 1228-1230. 